\title{
Urban Immigrant Diversity and Inclusive Institutions
}

\author{
Thomas Kemeny* $^{* \dagger}$ and Abigail Cooke ${ }^{\dagger \dagger}$ \\ $\dagger$ University of Southampton \\ ${ }^{\dagger}$ University at Buffalo, SUNY
}

January 13, 2017

\begin{abstract}
Recent studies identify a robust positive correlation between the productivity of urban workers and the presence of a diverse range of immigrants in their midst. Seeking to better understand this relationship, this paper tests the hypothesis that the rewards from immigrant diversity will be higher in metropolitan areas that feature more "inclusive" social and economic institutions. Institutions ought to matter because they regulate transaction costs, which in principle determine whether or not diversity offers advantages or disadvantages. We exploit longitudinal linked employer-employee data for the U.S. to test this idea, and triangulate across two measures that differently capture the inclusiveness of urban institutions. Findings offer support for the hypothesis. In cities with low levels of inclusive institutions, the benefits of diversity are modest and in some cases nonexistent; in cities with high levels of inclusive institutions, the benefits of immigrant diversity are positive, significant, and substantial. We also find that weakly inclusive institutions hurt natives considerably more than foreign-born workers. These results confirm the economic significance of immigrant diversity, while suggesting the importance of local social and economic institutions.
\end{abstract}

Disclaimer: This work was produced while the authors were Special Sworn Status researchers in a Federal Statistical Research Data Center. Any opinions and conclusions expressed herein are those of the authors and do not necessarily represent the views of the U.S. Census Bureau. All results have been reviewed to ensure that no confidential information is disclosed.

Acknowledgments: We thank Bert Grider and Billy Wisniewski at the U.S. Census Bureau for help with disclosure avoidance review, and Kyle Walker and Helga for sharing their ordinance data. This paper has been improved as a result of insightful comments by Max Nathan, Olmo Silva, Andrés Rodríguez-Pose, conference participants at Oxford and Cambridge, and four anonymous reviewers. This work has been supported by U.S. National Science Foundation grant BCS-1359768. The research uses data from the Census Bureau's Longitudinal Employer Household Dynamics Program, which was partially supported by the following National Science Foundation Grants SES-9978093, SES-0339191 and ITR-0427889; National Institute on Aging Grant AG018854; and grants from the Alfred P. Sloan Foundation.

\footnotetext{
*University of Southampton; email: t.e.kemeny@soton.ac.uk
} 


\section{Introduction}

The United States is home to one in five international migrants (Özden et al., 2011), and these individuals disproportionately reside in metropolitan areas (Wilson and Svajlenka, 2014). City-regions like New York, Los Angeles, and Miami lie at the extreme of the resulting immigrant diversity, with approximately one in three residents born abroad, ${ }^{1}$ and with scores of sending countries represented among the foreign born population (Ruggles et al., 2010, authors' calculations). Birthplace heterogeneity is also present and growing among smaller and less obviously cosmopolitan cities. For instance, one elementary school in the Buffalo-Niagara Falls metropolitan area - the 50th largest urban region in the country, and the location of one of this study's authors - reports that its students were born in more than 70 different countries. ${ }^{2}$

The economic implications of this diversity are the focus of a growing body of research, seeking to better understand its impacts on work and urban quality-of-life. Studies of the former topic, like the present one, are chiefly motivated by theory predicting that heterogeneity, defined broadly, should either enhance or impair worker productivity. Theorists of complex systems (Page, 2008); organizations (Huberman, 1990); and cities (Jacobs, 1969) assert that interactions among agents with distinctive heuristics and perspectives can improve problem solving and stimulate innovation. Psychologists identify additional dimensions to this relationship, suggesting that agents in diverse groups can find it difficult to establish common ground (Tajfel, 1974; Turner et al., 1987). Absent shared perspectives, agents face higher transaction costs, and are more likely to engage in rent-seeking behavior, which stands to reduce economic performance (Van Knippenberg and Schippers, 2007). Synthesizing these ideas, a model emerges in which diversity implies latent economic advantages and disadvantages whose realization depends on the cost of interaction (Kemeny, 2014).

The purpose of this paper is to test this model. If the model captures the underlying mechanisms at work, the effects of urban immigrant diversity on productivity will depend on institutions, defined as "the humanly devised constraints that structure po-

\footnotetext{
${ }^{1}$ U.S. Census Bureau, 2010-2014 American Community Survey 5-Year Estimates, "Selected Characteristics of the Native and Foreign-Born Populations" available from the American FactFinder website. The population of the Miami metro area is nearly $40 \%$ foreign-born (authors' calculations).

${ }^{2}$ Buffalo PS 45 International School: http://www.buffaloschools.org/InternationalSchool45.cfm
} 
litical, economic and social interaction." (North, 1991, p.97). More specifically, we test the hypothesis that the benefits of diversity ought to be larger in regions where institutions are "inclusive" (Acemoglu and Robinson, 2012), meaning that they lower the costs of interaction in a society consisting of different groups. With few exceptions, existing empirical studies at the urban scale have not measured such institutions, instead testing more generally for the existence and direction of spillovers from diversity. These studies mostly conclude that diversity and productivity are robustly positively related, leading researchers to suggest that immigrant diversity in cities generates tangible economic benefits (Ottaviano and Peri, 2006; Nathan, 2011; Bellini et al., 2013; Suedekum et al., 2014; Trax et al., 2015; Kemeny and Cooke, 2015; Elias and Paradies, 2016). Hence, one reason to examine the moderating role of institutions is that it provides the opportunity to estimate a model of diversity's economic impacts that is, compared to much of the extant empirical work, closer to theory.

The present paper also extends the work of two extant studies that do consider the connections between institutions, diversity, and economic outcomes at a subnational scale: Alesina and La Ferrara (2005), and Kemeny (2012). It does so in three main ways. First, it offers new and improved measures of local institutions, triangulating across these in order to have more confidence that they capture the underlying latent variable of interest. Second, in keeping with recent contributions in the literature, notably Bakens et al. (2013), Trax et al. (2015), Kemeny and Cooke (2015), and Elias and Paradies (2016), it uses an empirical approach that accounts for a wide range of potential confounding factors. Third, it unpacks overall estimates to consider how institutions and diversity operate differently for natives and foreign-born workers. With these advantages, estimates in this paper should provide stronger evidence on the role of diversity in shaping worker productivity, and on the role of institutions in this relationship.

We exploit variation over both time and space to identify the context-specific effects of diversity on productivity. Leveraging the time dimension, we estimate how workers' wages (our proxy for productivity) respond to annual changes in the diversity present in their city, and also in their workplace. Differences in cities' institutional context allow us to consider how the relationship between wages and diversity vary across workers in more and less inclusive cities. We limit attention to job 'spells' in which individual workers 
remain in a single workplace and city for at least two years. This permits the estimation of fixed effects models whose chief virtue is their ability to absorb bias from stationary unobserved heterogeneity at multiple scales, and in so doing address concerns of bias from sorting and other selectivity issues present in earlier work (Kemeny, 2014; Lewis and Peri, 2014; Combes et al., 2008). Additionally, we use the two-step generalized method of moments (GMM) fixed effects estimator with lagged internal instruments to help account for remaining endogeneity issues.

We draw on data from various sources to accomplish these tasks. Information about workers and workplaces comes from a version of the U.S. Census Bureau's confidential Longitudinal Employer-Household Dynamics (LEHD), a matched employer-employee dataset for the U.S. covering nearly all employees in 29 states on a quarterly basis between 1991 and 2008. Our first measure of inclusive institutions captures metropolitan-specific manifestations of bonding and bridging forms of social capital. The second describes pro- and anti-immigrant ordinances enacted by local governments. In distinctive ways, each sheds light on the opportunities for city residents to interact and residents' attitudes regarding those who differ from them, with the ordinance measure more specifically capturing a formalization of residents' attitudes about the presence of immigrants in their locality.

Across our two very different measures of institutions we find consistent evidence in support of our hypothesis. Workers living and working in cities featuring weakly inclusive institutions receive only modest, and in some cases statistically insignificant wage gains in association with the rising diversity in their cities. Meanwhile worker productivity in cities with inclusive institutions responds sharply to shifts in metropolitan immigrant diversity. In short, the inclusiveness of local institutions strongly moderates the realized economic value of immigrant diversity. Exploring disparate impacts by nativity, we find that natives in cities that have enacted anti-immigrant ordinances receive no diversity bonus, while productivity among immigrant workers in such cities remains positively linked to diversity, albeit less strongly than for workers in more inclusive locations.

The remainder of the article is structured as follows. Section 2 reviews relevant literature on the local economics of immigrant diversity and institutions. Sections 3 and 4 describe the empirical approach taken in this paper, and the data used. Section 5 presents results. Section 6 concludes. 


\section{Diversity, Productivity and Institutions: The Literature}

Suppose that interactions among members of a heterogeneous population contain the potential to generate both economic advantages and disadvantages. But interaction varies in its costliness, and, all else equal, transactions among individuals who share a common background are less costly than transactions among individuals without such commonalities. It follows that both rewards and costs are higher when interacting with people who are different.

These ideas have been explored by a wide array of social scientists. Psychologists, as well as scholars of organizations and other complex systems assert that behind people's demographic characteristics lie deeply rooted differences in heuristics and perspectives (Nisbett et al., 1980; Clearwater et al., 1991; Thomas and Ely, 1996; Page, 2008). Heuristic diversity can improve problem solving by creating a wider map of possible solutions (Hong and Page, 2001, 2004), as well as by fostering the cross-pollination of ideas, leading to novelty (Aiken and Hage, 1971). This enhanced capacity for problem solving ought to manifest itself in higher productivity. On the other hand, psychology's 'social identity theory' considers that populations composed of heuristically heterogeneous agents will find it harder to achieve trust and to generate shared understanding. Immediate consequences are that it will be more costly for workers to cooperate, and rent-seeking behavior will be more prevalent (Byrne, 1971; Harrison and Klein, 2007), which should inhibit productivity (Turner et al., 1987; Chatman and Flynn, 2001). This prediction has been borne out in relation to economic growth in ethnically-fractionalized developing countries (Alesina and Drazen, 1991; Easterly and Levine, 1997; Alesina and La Ferrara, 2005; Montalvo and Reynal-Querol, 2005).

Over the last decade, economic geographers and regional scientists have begun considering the impacts of diversity at the metropolitan scale, focusing mainly on immigrant diversity. The emergence of this agenda can be rationalized in a few ways. First, though immigrant or birthplace diversity is just one among many potential sources of heuristic heterogeneity, urban immigrant diversity has expanded considerably in recent years in a wide range of economies, and touches on a topic of perennial academic and popular signifi-

cance. Second, influential urbanists like Jacobs (1969) and Bairoch (1991) offer celebratory 
accounts of the economic virtues of various forms of diversity, analogously premised on the benefits associated with the city's capacity to act as an intellectual petri-dish. And most specifically, economic geography is premised on the idea that crucial economic interactions - especially those for which there is a central role for creativity and complex problem solving - cohere at a scale that is external to individual teams and firms but internal to metropolitan areas (e.g., Audretsch and Feldman, 2004; Moretti, 2012; Fujita and Thisse, 2013; Storper, 2013). According to this logic, interactions among a demographically and therefore heuristically - diverse urban populace ought to enhance problem solving, creativity and innovation. Hence, cities that are more immigrant-diverse ought to have higher productivity, as long as the negative externalities associated with diversity do not overwhelm the benefits.

Scholars have sought to measure the existence of spillovers from immigrant diversity in cities, considering impacts on productivity, innovation, and entrepreneurship. ${ }^{3}$ Though results vary by country and approach taken, a wealth of studies find evidence consistent with the idea that immigrant diversity augments worker and firm productivity (Ottaviano and Peri, 2006; Bellini et al., 2013; Bakens et al., 2013; Suedekum et al., 2014; Kemeny, 2012; Nathan, 2011; Longhi, 2013; Alesina et al., 2013; Lee, 2014; Nathan, 2015). Recent contributions have sought to address bias from confounding factors, including non-random worker selectivity, or sorting (Bakens et al., 2013; Kemeny and Cooke, 2015; Trax et al., 2015; Elias and Paradies, 2016). In the case of Trax et al. (2015) for Germany, and Kemeny and Cooke (2015) for the U.S., the positive association between urban immigrant diversity and productivity remains after accounting for sorting behavior, diversity in the workplace, and other sources of heterogeneity at the individual, workplace and city scales.

Despite this growing econometric sophistication, few studies to date account for variation in the cost of interpersonal interaction. The theory above suggests that the cost of interaction will determine the extent of realized economic advantages or disadvantages. When interactions can be cheaply conducted, trust and cooperation should facilitate the realization of the kinds of benefits that are latent in diversity. When interactions across individuals born in different countries can only be conducted at a high cost, both the number of quality of such interactions ought to be reduced, resulting in diminished productivity.

\footnotetext{
${ }^{3}$ For recent reviews of this literature, see Kemeny (2014) and Nathan (2014).
} 
It should be expected that some component of these costs are idiosyncratic - internal to individuals, based on their preferences and background (e.g., Valentine and Sadgrove, 2014). Workplaces and firms also plausibly generate their own regularities around such costs. But, as historians, economists, and other social scientists have argued for decades, there are systematic factors above such scales that shape the costliness of interaction. Most famously, North (1991) argues that, in an economy involving a complex division of labor, significant territory, and agents who are not tied by kinship, the market requires coordination to overcome problems of agency and enforcement. Institutions are the system of formal and informal rules and norms facilitating this coordination, strengthening trust and reducing defection so as to enable interactions among a diverse and specialized population. Echoing this theme, Acemoglu and Robinson (2012) argue for the importance of "inclusive" institutions, especially as economies approach the technological frontier. Formal and informal institutions are inclusive when, in Robinson's words, they "create the incentives and opportunities necessary to harness the energy, creativity and entrepreneurship in society" (2013, p.1).

Applied more narrowly to issues of heterogeneity, this suggests that inclusive institutions should be those that reduce the costs that people born in different countries face in interacting with each other. When such institutions are present, they should minimize the disadvantages associated with cross-cultural interaction, and better enable the realization of benefits. This moderating role for institutions is more than intuition: studies of the impacts of ethnic fractionalization in poor countries find that institutions like democratic governance and contract enforceability can play a decisive role in enabling economic development (Easterly and Levine, 2001; Collier, 2000). It should be noted that these studies consider ethnicity, not birth country; they also take as their focus poor countries in Africa, not American cities. Still, their results suggest that institutions ought to shape the impacts of immigrant diversity.

It is also worth noting that development economists examining institutions at the national scale operationalize these forces largely using measures of formal laws regarding contracts and intellectual property. Such formal legal structures tend to be determined at the national level, but theorists' conception of institutions is expansive, equally featuring informal norms and shared attitudes. This is especially important when studying the 
subnational scale, where even within a larger national context of formal laws, one might expect considerable local variation. Despite their informality, a great deal of theory and evidence point to the crucial role these play in shaping the nature of market transactions and thus local development trajectories (Storper, 1995; Rodríguez-Pose, 1999; Morgan, 2007; Storper et al., 2015). Furthermore, though most formal legal institutions apply nationally, as will be discussed in detail later in this study, there can also be substantial subnational variation in legal ordinances that shapes local institutional contexts. Thus, between the formal laws and informal norms and attitudes, we might expect substantial local variation in the inclusiveness of institutions.

Motivated by these arguments, this paper tests the following primary hypothesis: the effects of immigrant diversity on worker productivity should be stronger in metropolitan locations that feature more inclusive institutions.

Additionally, we conjecture that immigrants to the U.S. may be more open to interactions with others than natives (especially in locations that contain large numbers of natives who may not be particularly welcoming to their presence), rendering their effective transaction costs systematically lower than that manifested by native residents. By the very act of choosing to emigrate to the U.S., immigrants demonstrate at least some openness to the different culture present in their host country, relative to natives who have remained in their country of birth. Because natives remain a considerable majority in most urban locations, we consider that overall measures of local institutions may inadequately capture immigrants' attitudes towards transacting with others. Based on this idea, we also explore whether the relationship between immigrant diversity and wages is more strongly shaped by the institutional context for native-born workers than for immigrants.

Only two known studies address closely related topics at a subnational scale. Alesina and La Ferrara (2005) measure the relationships between ethnic diversity and population growth in U.S. counties, proxying for institutions using local income levels. They find that poor, ethnically heterogeneous counties tend to experience declines in population, whereas in wealthy, diverse locales, this relationship is weaker, and in some models, it turns positive. This suggests a positive role for stronger institutions in modulating the effects of diversity on local economies, a finding broadly consistent with the primary hypothesis of the present paper. The closest study to the current paper is Kemeny (2012), which demonstrates that 
the association between birthplace diversity and wages is considerably larger in cities endowed with higher levels of generalized trust and social capital. While suggestive, that paper does not account for a large range of potentially relevant but unobserved factors that distinguish locales, establishments, and individuals; moreover it is largely cross-sectional, and as such is less able to capture how diversity and wages co-move, which studies like Longhi (2013) have shown to be critical.

\section{Empirical Approach}

This section describes the approach taken to measuring the relationship between diversity and productivity. In relation to the literature described in the previous section, a number of features are especially important. First, our approach aims to account for a wide range of hard-to-observe and potentially confounding features of individuals, establishments and cities. Second, it facilitates observation of the co-movement of diversity and productivity over time. Third, it distinguishes between potential diversity impacts arising from the city scale and the workplace scale.

Our aim is to measure how individual workers' productivity respond to changes in the diversity that surrounds them. Following much of the existing literature, we proxy for productivity using information on worker wages, a choice premised on practical but defensible grounds. Though the two are unlikely to be identical, studies like Combes et al. (2005) argue that rising productivity is likely to be expressed in higher wages. Meanwhile, recent work indicates that establishment level productivity and wages exhibit similar elasticities with respect to city size (Combes et al., 2010).

We focus attention on the work spells of 'stayers' - individuals that remain in a single workplace (and thus metropolitan area) for at least two years. As these workers are fixed in place, variation comes from the panel structure of our data, and more specifically from the shifts around these workers in the birthplace composition of the cities in which they live, and the establishments in which they work. We estimate the following equation:

$$
\ln (w)_{i p j t}=d_{j t} \beta++d_{p j t} \gamma+X_{i p j t}^{\prime} \delta+E_{p j t}^{\prime} \theta+C_{j t}^{\prime}+\mu_{i p j}+\eta_{t}+\nu_{i p j t}
$$

where, $\ln (w)$ represents the $\log$ annual wages of an individual worker $i$ in establishment $p$ located in metropolitan area $j$ at time $t ; d_{j t}$, a key independent variable of interest, 
measures city-specific immigrant diversity; $d_{p j t}$ measures diversity at the level of the establishment; $X^{\prime}$ represents time-varying measures of worker-specific characteristics; ${ }^{4} E^{\prime}$ describes a vector of dynamic employer characteristics; and $C^{\prime}$ indicates time-varying characteristics of a worker's metropolitan area. The fixed effect, $\mu_{i p j}$, represents a key feature of our approach. Because we analyze only stayers, Equation (1) accounts for the effects of unobserved permanent characteristics of not just the individual workers themselves, but also the establishments where they work, and the regional economies in which they live. At the individual level, such pertinent stationary unobserved heterogeneity could be present as a consequence of differences in workers' innate ability, intelligence, or motivation. Material establishment-specific features could include deep-rooted differences in capital intensiveness or product quality. And at the level of metropolitan regions, differences in specialization, agglomeration, and other factors could be relevant, if hard to observe and relatively non-dynamic. Returning to Equation (1), $\eta_{t}$ represents unobserved time-specific shocks that exert uniform impacts across all individuals, such as as business cycles; and $\nu_{i p j t}$ is the standard error term. Applying the fixed effects estimator, Equation (1) explores how an individual's productivity responds to changes in the level of immigrant diversity present in her metropolitan area, while it accounts for major sources of spurious correlation that might bias estimates of the impact of diversity on wages that rely only on observable features.

One challenge in measuring the relationship of interest comes from recent work in urban economics on spatial equilibrium. Following arguments rooted in Roback (1982), in a system of cities where firms and workers are relatively free to choose locations, estimates of Equation (1) that demonstrate a positive and significant relationship between wages and diversity would be unable to distinguish between two interpretations: (a) that diversity generates spillovers that augment productivity, or (b) that workers consider diversity to be an unpleasant disamenity, and require higher pay to endure it. The standard remedy is to relate diversity not just to wages but also to rents. Higher wages and rents in response to diversity shocks would then be interpreted as confirming (a), whereas results indicating higher wages and lower rents corresponds to (b).

\footnotetext{
${ }^{4}$ Of which, in practice, we have none since the individual charateristics available in the LEHD data such as sex, race, and birth year - are time-invariant.
} 
Our data does not permit us to observe workers' living arrangements. Nonetheless, we believe our chosen approach can shed light on diversity's potential productivity impacts. Responding narrowly to spatial equilibrium concerns, Moretti (2004a) and Acemoglu and Angrist (2001) point out that, in areas where firms sell goods and services beyond their immediate locality, higher nominal wages must indicate higher average worker productivity. While firms in nontradable activities may reference local prices, traded-goods firms face national prices. If they paid higher wages with no compensating productivity advantages, firms would be forced to relocate to locations offering some form of compensating differential - whether in the form of cheaper land or higher quality-of-life. Hence, detecting a positive relationship between diversity and wages ought to indicate productivity benefits in regions containing tradable activities. More broadly, while worker mobility, land markets and consumption are clearly important and interlinked features of urban systems, it remains far from clear that these features relate in the specific ways that canonical spatial equilibrium models suggest. Strong questions have been raised about the sequencing of these models (Storper and Scott, 2009), as well as about the lack of evidence supporting their most basic prediction: a gradual movement toward utility equalization across cities in the US urban system (Kemeny and Storper, 2012). In short, it is far from clear that reality sufficiently conforms to this body of theory, and there is good reason to believe that rising wages ought to signal productivity growth.

To determine whether or not the relationship between immigrant diversity and productivity depends on the inclusiveness of local institutions, we estimate Equation (1) separately for workers inhabiting cities that feature institutions that are distinctly inclusive or exclusive. Because of institutions' capacity to regulate transaction costs, we expect that the relationship between diversity and wages ought to be more strongly positive for workers inhabiting cities with more inclusive institutions. For workers in cities with exclusive institutions, we expect the relationship to be weaker, nonexistent, or even negative. To determine if institutions play more of a role in shaping native-born than immigrants' diversity-productivity relationship, we estimate Equation (1) separately for immigrants and native born workers in both inclusive and exclusive instution cities. We expect the difference between the institutional contexts to be greater for natives than immigrants. The next section describes our data, analytical sample, and the construction of 
our measures of diversity and institutional inclusivity.

\section{Data}

Our primary data source is the U.S. Census Bureau's confidential Longitudinal EmployerHousehold Dynamics (LEHD) Infrastructure files, the sole source of matched employeremployee data for the United States. The LEHD program integrates administrative records from state-specific unemployment insurance (UI) programs with Census Bureau economic and demographic data, providing a nearly universal picture of jobs in the U.S. (McKinney and Vilhuber, 2011). The version of the data available for this study covers over 90 percent of all workers in 29 states, on a quarterly basis starting as early as 1991 and continuing though $2008 .^{5}$

\subsection{Analytical Sample}

To estimate the relationship between immigrant diversity and a worker's wages, we must first assign workers to workplaces, and thereby to Metropolitan Core-Based Statistical Areas (CBSAs). ${ }^{6}$ This assignment serves a few purposes. It permits construction of diversity measures for each workplace and city. It is also required to help determine which workers to include in the analytical sample.

Assigning workers to establishments in the LEHD data is a nontrivial task. For workers in jobs at single-unit firms - those with only one plant, outlet, or office - knowing the employer tells you the place of work, because there is only one possible location. However, for workers employed at multi-unit firms, knowing the employer cannot definitively reveal the place of work. About 30-40 percent of workers included in the LEHD data work at multi-unit firms (McKinney and Vilhuber, 2011). The LEHD includes a file (U2W) that, for each person employed in a multi-unit firm, provides ten work-unit imputations. Imputations are based on the distance between workers' homes and establishment locations, and the distribution of employment across the establishments within the multi-unit employer, leveraging non-imputed establishment-worker data available for the state of Minnesota

\footnotetext{
${ }^{5}$ States used in our project: AR, CA, CO, FL, GA, HI, IA, ID, IL, IN, LA, MD, ME, MT, NC, NJ, NM, NV, OK, OR, SC, TN, TX, UT, VA, VT, WA, WI, WV.

${ }^{6} \mathrm{CBSAs}$ reflect economically-integrated urban regions. Throughout, we use the terms 'city', 'metropolitan area', and 'region' interchangeably.
} 
to generalize to the remainder of states (McKinney and Vilhuber, 2011, see Chapter 9). Because of the number of observations and because work location structures much of the data processing necessary for our analytical strategy, estimation with multiple imputations is impractical. Instead, for each job in a multi-unit employer, we assign each worker to their most frequently imputed establishment, and in the case of ties, random assignment between the tied modal units. ${ }^{7}$

Having assigned all workers to establishments across time, we can then identify work spells upon which to estimate Equation (1). For each worker in LEHD, we include a maximum of one work spell across our study period. We select the longest such spell, as long as it exceeds two consecutive calendar years. This two year minimum allows us to smooth quarterly earnings to an annual measure and observe potential changes in wages over time. Workers with no spells lasting at least two years are excluded from our analytical sample (but not our measures of diversity).

We aggregate from quarters to years, and link workers to worker and workplace characteristics available as part of LEHD. Establishment features include location, total annual employment, and six-digit NAICS industry. Worker characteristics include wages, country of birth, birth year, sex, and race. Following common practice, for the purpose of analysis we limit the age range of workers to be over 16 and less than 66 years old. We exclude workers with very low wages - those below the 5th percentile of the wage distribution on the basis that LEHD's inclusion of all workers earning at least one dollar in a quarter captures some very low earners potentially operating under irregular employment situations. We believe that the inclusion of these extremely low earners could reduce the signal to noise ratio in the relationship of interest. We also drop workers who are simultaneously employed in multiple jobs, so that we can clearly identify the source of any establishmentspecific diversity effects. Finally, to ensure that our measure of workplace diversity is

\footnotetext{
${ }^{7}$ The vast majority of all jobs can only be assigned to a single city, either because they occur in singleunit employers or multi-unit employers where all the establishments are located in the same city. This raises our confidence that our diversity measures capture workers who actually work in each city. Furthermore, we have no reason to believe that there would be any non-random error related to birthplace that would systematically bias our diversity measures. We test the quality of our assignment process in two ways. First we relate our measure of metropolitan birthplace diversity to one derived using $5 \%$ public-use Census extracts, with typical correlation coefficients around 0.9. Second, we compare estimates of Equation (1) generated from our full sample to those derived from a sample limited to workers in single-unit firms only, where there can be no misattribution of workers to workplaces. Doing so, we find broad consistency across measures of diversity, in terms of signs, significance, and magnitudes. These checks indicate that any misattribution from our assignment procedure is not materially affecting our findings.
} 
informative, we restrict the sample to jobs at establishments with at least ten employees.

Though the resulting sample is very large, our choices imply some limits to generalizability. We cannot describe the relationship of interest for workers with extremely tenuous labor market attachment (those without any two year UI-recorded job spell), very low wages, those working in very small establishments, and of course, those who are self-employed. Given the focus on metropolitan areas, the sample also has no purchase on the shape of this relationship in rural towns and small municipalities. Finally, our sample is not perfectly nationally representative, since the version of the LEHD data we had access to excludes two fifths of the states. However, the states that are represented in the sample vary along a number of important dimensions that reflect the larger national system of cities. They are large and small; populous and relatively uninhabited; drawn from every region of the country; home to longstanding gateway cities and nontraditional hosts to immigration. We believe that this offers a wide snapshot of workers in American cities.

\subsection{Measuring Diversity}

Researchers commonly measure birthplace diversity using the following index of 'fractionalization':

$$
\text { Fractionalization }_{j}=1-\sum_{r=1}^{R} s_{r j}^{2}
$$

where $s$ is the proportion of residents in city $j$ who were born in country $r$; and $R$ is the number of different countries represented among residents of that city. The index nears zero as diversity decreases and its maximum value approaches one as heterogeneity increases; it is often described as measuring the probability that two randomly-drawn individuals in a location were born in different countries. This index has been used to capture a wide variety of categorical forms of diversity, including language, birthplace, race and ethnicity (see, for example, Taylor and Hudson, 1972; Easterly and Levine, 1997; Knack and Keefer, 1997; Ottaviano and Peri, 2006; Sparber, 2010). The pervasiveness of this measure in diversity research is no doubt related to its simplicity, as well as its ability to capture both the breadth of countries from which individuals originate, as well as the sizes of these different country groups in a given location. 
Because it is the most widely-used measure in the field, we estimate metropolitan- as well as establishment-specific levels of diversity using the fractionalization index, using the universe of LEHD-coded worker birthplaces in a metropolitan area or work unit. ${ }^{8}$

Workers' birthplaces and locations in workplaces and thus metropolitan areas form the basic inputs into annual fractionalization indices. To calculate measures of diversity at the city level, we first narrow our list of CBSAs to those that do not cross state boundaries with states unavailable to our project. Thus, although jobs located in Newark, NJ are included in our raw data, we drop them because they are part of the CBSA for New York City that also includes jobs in New York State and Pennsylvania, to which we do not have access. We do include CBSAs straddling multiple states to which we do have access, such as Texarkana in Texas and Arkansas.

Though the metropolitan area is our primary focus in this paper, theory suggests diversity within work units can have positive or negative relationships with productivity, a possibility we would like to control for in our models. Having assigned workers to establishments, we can also calculate the fractionalization measure for each establishment in each year. One difference is that instead of weighting each person's contribution to birthplace diversity evenly (as we do in the city measures), we weight each person's contribution depending on how many quarters they work in a particular establishment. If they worked half the year in one establishment and half the year in another, then they count as half a person in the diversity measures of each establishment for that year.

\subsection{Measuring Inclusive Institutions}

This paper assumes that there are regularities in the level of transaction costs in different cities, and that these regularities are a function of what Acemoglu and Robinson (2012) call 'inclusive institutions'. We build two distinctive indicators: a composite measure of social capital, and a variable that captures locality-specific ordinances aimed at immigrants.

\footnotetext{
${ }^{8}$ Kemeny and Cooke (2015) demonstrate that estimates of the relationship between diversity and wages are not strongly dependent on choosing the standard fractionalization measure, as against an entropy index, decompositions of the fractionalization measure in the manner of Alesina et al. (2013), or measures that distinguish the simple share of foreign born from the range of countries present.
} 


\subsubsection{Social Capital}

We follow Woolcock and Narayan (2000) in defining social capital as "the norms and networks that enable people to act collectively" (p.226). Putnam (2000) famously unpacks this idea into two categories: bonding, which captures such norms and networks within groups of similar individuals in a community; and bridging, which indicates these capacities among members of disparate groups. As Malecki (2012) argues, we can expect social capital to vary at the regional or metropolitan scale in ways that affect trajectories of economic development. In the context of this paper, our interest is in its potential moderating role: locations with stronger manifestations of social capital ought to better enable people born in different countries to act collectively at a lower cost, and in so doing, they will reap greater rewards from a given quantity of immigrant diversity.

Combining secondary data from various sources, we construct a composite indicator of social capital, adapting an approach proposed by Rupasingha and Goetz (2008). To capture aspects of bonding social capital, we use data from County Business Patterns to count the number of various kinds of associations, including social, advocacy, business, professional, labor, and political organizations. To ensure comparability across cities of various size, these counts are scaled per ten thousand residents. We complement these with an analogous count measure of what Oldenburg (1989) describes as 'third places' (the home being the first, and workplace being the second) that can enable both bonding and bridging forms of social capital. Again relying on County Business Patterns, the third places we consider include speciality food shops, restaurants, cafés, bars, hair salons, corner stores, golf clubs, fitness centers, bowling alleys, and sports clubs. To describe civic participation, we use two pieces of information drawn from Rupasingha and Goetz (2008): county-level mail response rates for the 2005 American Community Survey (ACS); and county voter turnout for the 2004 presidential election.

We perform principal components factor analysis, seeking to generate a compound measure on which to split the sample. The inputs cohere into a single factor with an eigenvalue of 2.36, explaining 59 percent of the overall variance. Prior to varimax rotation, the next largest factor has an eigenvalue of 0.67 , and is not retained post hoc. Factor loadings, showing the correlation of each input variable and the resulting composite factor, 
are shown in Table 1. The table also shows that each of the inputs offer something distinct in the definition of the larger factor, though voter turnout is the least unique.

[Table 1 about here.]

Though it would be possible to build a measure of social capital that varies over time, we elect to build a single indicator for each metropolitan area, centered on the year 2007, on the basis that we expect social capital to be highly stable across time. ${ }^{9}$ We check this assumption by comparing a version of our index for 2007 to indicators built by Rupasingha and Goetz for 1990, 2000 and 2005. ${ }^{10}$ These city-level correlations between measures of social capital across time are extremely strong: the weakest relationship is between 2007 and 1990 (0.90); the strongest is between 2007 and 2005, with a coefficient of 0.94. This intertemporal consistency validates our use of an indicator of metropolitan social capital measured at a single point in our study period.

Seeking to provide a stark contrast between cities that feature inclusive institutions and those that do not, for our analysis we select the cities that fall into the lowest and highest terciles of this social capital measure. Here, we interpret cities that scored in the lowest tercile of social capital as offering the least inclusive institutions, whereas those cities in the highest tercile feature institutions that are highly inclusive. To illustrate with concrete examples, Table 2 lists the ten CBSAs that have the highest and lowest values of our social capital index.

[Table 2 about here.]

\subsubsection{Pro- and Anti-Immigrant Ordinances}

The second measure of inclusive institutions makes use of data describing local government policies that either restrict or enable the behavior of immigrants. Since the early 2000s, municipal governments in the U.S. have increasingly considered and enacted laws that

\footnotetext{
${ }^{9}$ In fact, some researchers assert that American social capital is in decline (cf. Putnam, 2000; Rahn and Transue, 1998; Stolle and Hooghe, 2005). To the extent that this is occurring, it is undoubtedly happening very slowly, and there is little to suggest it has proceeded idiosyncratically from one city to another.

${ }^{10}$ To maximize comparability, for this exercise we construct a version of our index that directly mirrors Rupasingha and Goetz's measure, in which we include a narrower range of types of third places - however, the social capital measure we ultimately use in our analysis is closely related.
} 
target immigrants, a shift that may be best understood as an outgrowth of grassroots responses to residents' perceptions of immigrants, and especially undocumented immigrants (Varsanyi, 2008; Walker and Leitner, 2011). Immigrant-penalizing laws include those seeking to punish employers who hire undocumented immigrants, ones that amend housing codes to restrict crowding, some that restrict the use of languages other than English, and still others that require immigration checks in response to events ranging from arrests to new firm births (Rodriguez, 2008). Meanwhile, other locations have used legislation to more actively welcome immigrants, enacting 'sanctuary' laws that prohibit immigration checks or regulations that extend voting rights for immigrants in local elections (Walker and Leitner, 2011).

Although these ordinances are formally aimed at regulating undocumented immigrants, evidence suggests that they affect the wider foreign-born population, regardless of the status of their documentation, in that those who look and sound different will live in a context marked by real risks from police and other residents engaged in profiling (see for example, Nguyen and Gill, 2015). Nonetheless, our primary interest is not in how these ordinances may or may not have a direct legal effect on individuals. It lies instead in their utility as an indicator of local attitudes towards immigrants, reflecting priorities to publicly debate and potentially adopt an official stance on the presence of immigrants. We take proimmigrant ordinances as signals of an inclusive institutional context, whereby lawmakers and community members felt the need to enact legislation that aims to foster greater integration and inclusivity towards those born abroad. By contrast, we interpret the presence of anti-immigrant ordinances to signal a community's strong reluctance towards bridging behavior with immigrants specifically. One important difference between these measures and our social capital index is that the ordinance-based measures capture not just general inclusiveness, but more precisely they gauge inclusiveness towards individuals born in foreign countries.

The ordinance measures used here start from a bespoke national dataset assembled by Walker and Leitner (2011). These data are locality-specific, covering 369 individual ordinances proposed or implemented as last as February 2009. Ordinances emerge from both municipalities and counties, and have been coded as either "pro-" or "anti-immigrant." We aggregate pro- or anti-immigrant ordinances to the metropolitan scale, weighting by pop- 
ulation in the process. Since metropolitan areas frequently include several municipalities and often multiple counties, not all of which have passed immigrant-related ordinances, the resulting metropolitan-level indices have uneven coverage. Some CBSAs have laws covering only a very limited share of the total population. Other areas contain a patchwork of places that variously offer pro- and anti-immigrant ordinances. Seeking to maximize the signal to noise ratio, we classify CBSAs as being pro-immigrant only when more than 50 percent of their population is covered by pro-immigrant laws. We use the same threshold to classify cities as anti-immigrant. This means we discard a host of metropolitan areas that either have no ordinances at all, have some which cover modest proportions of total residents, or are subject to an inconclusive mix of pro- and anti-immigrant laws. While this entails estimating our model on a restricted subset of cities, we view this as an acceptable tradeoff in that it ensures that we have captured truly distinct institutional features. Simply, we want to make sure that pro-immigrant metros are truly different from anti-immigrant metros, and to do so we need to eliminate ambiguous cases.

[Table 3 about here.]

As with our measure of social capital, we generate only one ordinance measure per metropolitan area, ignoring the time dimension in our primary data. We do so for substantive reasons. The passage of these laws cannot be seen as exogenous shocks acting on our outcome; they are instead manifestations of deeply-held community attitudes regulating interpersonal interaction. We consider that these attitudes ought to be relatively static across our study period, such that, even if an ordinance is passed in 2005, the sentiments and beliefs that give rise to it should still be latent in the community in earlier periods, at least in medium run.

For descriptive purposes, Table 3 reports the ten metropolitan areas that are most clearly pro- and anti-immigrant, based on the proportion of each region's population unambiguously covered by ordinances of a certain character. Cities with the widest coverage from pro-immigrant ordinances make up a diverse mix, including university towns (Madison); politically-liberal metropolises (San Jose), and smaller agricultural regions (Fresno). Locations with wide coverage from local anti-immigrant laws include larger Sunbelt regions (Houston and Charlotte), as well as smaller cities in the Rustbelt (Green Bay; Appleton). 


\subsection{Control Variables}

As section 4.2 makes clear, LEHD is very rich in terms of capturing nearly the full breadth of the workforce in great temporal detail. But it captures only a modest range of features of those individuals and their workforces, and our empirical strategy takes best advantage of both these strengths and weaknesses. Specifically, the inclusion of individual $x$ workplace $x$ city fixed effects means that unobserved factors at each of these levels - of which there could be many - ought not to bias our estimates of the relationship of interest, as long as those factors are relatively stationary. Additionally, we seek to include as many relevant time-varying control variables as possible. To capture changes in internal economies of scale, we include a measure of workplace-specific annual employment, drawn from LEHD. Owing to the absence of time-varying measures of individual worker characteristics in LEHD, the vector $X_{i p j t}^{\prime}$ is omitted from our actual estimating equation. At the metropolitan scale, we control for external economies of scale using a measure of overall city employment. We also seek to control for local educational spillovers using a CBSA-specific indicator of average educational attainment. To build this measure, we avoid using LEHD's individual-level imputed educational length indicator because, when aggregated to the metropolitan scale, imputed values are only weakly correlated with comparable non-imputed measures derived from 5 percent extracts of the Decennial Census. Instead, as in Moretti (2004b), we estimate the annual share of each CBSA's workforce holding at least a 4-year college degree, using 5\% public-use IPUMS extracts from the 1990 and 2000 Decennial Censuses, as well as 1\% samples from each year of the 2001-2008 ACS (Ruggles et al., 2010), interpolating between available years of data. Incomplete coverage of metropolitan areas in IPUMS reduces our sample of CBSAs from 232 to 163. The poor quality of the imputed LEHD education data also means we can not directly observe shocks to human capital in individual establishments. To the extent that such shocks might be correlated with shifts in immigrant diversity in the workplace, causal interpretation becomes more challenging at that scale. 


\subsection{Summary Statistics}

Table 4 presents descriptive statistics for key variables in our analytical sample, as well as salient static characteristics of the workforce, included in order to compare the overall sample to the larger US working population. The dependent variable throughout our analysis is the log of an individual worker's annual earnings, which in LEHD are drawn from Unemployment Insurance records. The average worker in our sample earns a little over $\$ 35,000$ annually, and is 40 years old. Sixty-seven percent of the sample is white, 84 percent is native-born, and 47 percent is female. These characteristics broadly reflect the overall U.S. economy (Lee and Mather, 2008; Social Security Administration, 2015). The average work spell in the sample lasts nearly 5 years.

[Table 4 about here.]

\section{Results}

This section presents estimates of the main relationship of interest: whether and how local institutions moderate the relationship between immigrant diversity and worker productivity. In each of the estimates that follow, we cluster standard errors at the establishment level, reasoning that workers' wages will be more strongly conditioned by sharing a common workplace than by simple co-presence within a particular metropolitan area.

\subsection{Main Estimates of the Moderating Role of Institutions}

Although the main contrast to be drawn is between workers who live in cities that have strongly and weakly inclusive institutions, for comparison purposes, we begin in the first column of Table 5 by presenting estimates for all workers in all cities in our analytical sample. In keeping with the prior studies reviewed in Section 2, results indicate that city diversity is positively and significantly related to wages. The other city-level covariates have the expected signs, showing evidence of externalities arising from human capital and scale. At the establishment level, diversity is positively related to wages, at a one percent level of significance. Workplace employment is also positive and significant, suggesting the 
presence of internal economies of scale. ${ }^{11}$

[Table 5 about here.]

In Columns 2 and 3 we report on our use of the social capital indicator to differentiate workers on the basis of the inclusiveness of their metropolitan institutional contexts. Workers in Column 2 live in cities that fall within the lowest tercile of social capital. Those in Column 3 live in cities in the highest tercile of social capital. Our main interest is the contrast between coefficients on our measure of urban immigrant diversity across these two groups. Though the estimated coefficient for city-level diversity is positive and significantly related to the wages of workers in both kinds of cities, the strength of the association varies considerably: the coefficient on metropolitan immigrant diversity for workers in cities in the highest tercile of social capital is seven times as high as for workers in the lowest. ${ }^{12}$

The fourth and fifth columns of results in Table 5 present estimates in which we capture variation in the inclusiveness of institutions using our measures of local immigrant ordinances. Column 4 presents estimates on the sample of workers residing in cities where at least 50 percent of the population is covered by anti-immigrant ordinances. The coefficient on city-level immigrant diversity is statistically insignificant. Column 5 shows results for workers in cities with at least 50 percent of the population covered by pro-immigrant ordinances. The coefficient for city level diversity is positive, significant and large. These results are broadly consistent with those found using the social capital indicator, though even more strongly differentiated. A logic for this larger gap is easily obtained: metropolitan areas in which a large subset of the population is covered by pro-immigrant ordinances have acted decisively to welcome immigrant in their midst. Whereas those marked by antiimmigrant laws are not simply weaker in terms of bridging - they have actively made their environment hostile to immigrants. This more pronounced gap in the spread of our ordi-

\footnotetext{
${ }^{11}$ Results in the first column of Table 5 are drawn from Kemeny and Cooke (2015). That paper demonstrates that this general relationship is robust to a wide range of measures of birthplace diversity; different subsamples; the inclusion of various control variables, including those measuring age and racial fractionalization, Bartik-style local demand shocks, and immigrant-specific measures of educational attainment.

${ }^{12}$ Our measures of institutions capture a phenomenon that is distinct from city size. Running models only on workers inhabiting cities above a threshold of one million residents, we found that, for workers in low social capital cities, the coefficient on city diversity is positive but not statistically significant at a 10 percent level, while the city diversity coefficient for workers in cities with high levels of social capital was very large and statistically significant at a one percent level.
} 
nance measure is reflected in its more pronounced moderation of the relationship between diversity and wages.

\subsection{Estimates of the Moderating Role of Institutions by Nativity}

Next we unpack the relationship of interest by nativity. That is, we estimate how nativeand foreign-born workers may be differently rewarded from the diversity in their midst on the basis of the institutions present in their local environment. It seems most plausible to expect variation of this kind for our ordinance measure: although pro- and especially anti-immigrant ordinances may reflect the attitudes of certain constituencies in the the native-born population, there far less reason to expect that they extend to immigrants themselves. Though they may reside in a hostile environment, immigrants may not share this xenophobia, and may indeed face quite low barriers to cross-cultural interaction.

[Table 6 about here.]

Table 6 explores this idea, estimating Equation (1) in pro- and anti-immigrant ordinance cities separately for native and foreign-born workers. The first and second columns of results present estimates for cities with anti-immigrant ordinances. For foreign-born workers in these anti-immigrant locales (Column 1), the coefficient on metropolitan immigrant diversity is positive and significant at a one percent level. Interestingly, for natives in these cities (Column 2), we detect no significant relationship between diversity and wages. This suggests that the very natives who have enacted exclusive institutions are locked out of the benefits associated with immigrant diversity. Columns 3 and 4 present results by nativity for workers in cities featuring pro-immigrant ordinances. In these cities, for native- and foreign-born workers alike, the coefficient on birthplace diversity is large, positive and significant at a one percent level. Thus, as well as comparing the average results across city types, it is interesting to consider how natives and foreigners fare with respect to diversity depending on where they live. Though foreigners in general may face lower transaction costs in interacting with people from different countries, spillovers from diversity are considerably higher in cities that feature pro-immigrant ordinances.

Though the clearest rationale for focusing on nativity comes from our ordinance measure, to support our results the next four columns repeat the process for our social capital 
measure. For workers in cities in the lowest tercile of social capital, Columns 5 and 6 present estimates for foreign- and native-born, respectively. Mirroring the pattern shown for the ordinance measures, foreign-born workers continue to receive wage benefits from urban diversity in cities with low social capital, whereas for natives there is no significant association between rising metropolitan birthplace diversity and wages. In cities with high levels of social capital (columns 7 and 8), both native and foreign-born workers enjoy considerably large urban diversity spillovers, significant at a one percent level. While these nativity-specific results offer insights into the distribution of any benefits arising from diversity, they are of particular interest in the present paper since they offer further support for institutions in moderating the relationship between diversity and productivity.

\subsection{Instrumental Variables Estimates}

Although our overall estimation approach accounts for a breadth of static unobserved factors, as well as systemwide dynamics like business cycles, estimates of Equation (1) remain vulnerable to shocks to individuals, workplaces, and cities that affect wages. To the extent that such idiosyncratic shocks are correlated with shifts in diversity, we may be attributing to diversity an effect that resides instead with these factors. For instance, workplaces that experience a rise in diversity may simultaneously invest in machinery that makes workers more productive. Without indicators to capture such investments, our estimates of the role of diversity in generating spillovers may be biased. The use of instrumental variables is no panacea, though with plausibly exogenous and sufficiently strong instruments, it supports more confident statements about the causal nature of the relationships at hand.

With this in mind, in Table 7 we present Generalized Method of Moments fixed effects (GMM FE) estimates of the relationship of interest for workers in cities that fall into the lowest and highest terciles of our social capital measure. We instrument for current-year diversity using deeper lags of city and workplace diversity. We opt for such 'internal' instruments mainly due to a lack of availability of external candidate instruments, particularly at the establishment scale. ${ }^{13}$ We performed extensive tests of the exclusion restriction on a

\footnotetext{
${ }^{13}$ We experimented with several external instruments for city immigrant diversity, including a longitudinal version of the shift-share 'predicted diversity' instrument that is widely used in (primarily cross sectional) studies of immigration and immigrant diversity (see, for instance, Card, 2001; Ottaviano and
} 
broad range of lags before finding candidates that did not emerge as significant predictors of the outcomes of interest, but which also permitted overidentification. We ultimately settled on three to five year lags for city diversity, and a two or four year lag for establishment diversity. The Kleibergen-Paap $F$-statistic, appropriate given no assumption of independent and identically-distributed errors, shows these instruments not to be weak, while results from the Hansen- $J$ test indicate joint exogeneity.

[Table 7 about here.]

As before, our primary interest is in the contrast between the coefficients on metropolitan immigrant diversity on the basis of the strength of local social capital. For those workers in cities in the bottom tercile of social capital (column 1), we report that urban immigrant diversity is unrelated to wages. In column 2 , for workers in cities with the highest social capital, the coefficient on metropolitan immigrant diversity is very large, positive and significant at a 1 percent level. These results broadly conform to the uninstrumented results, in terms of showing strong differentiation in the benefits from diversity in favor of cities that feature inclusive institutions. However they differ in indicating no benefits for workers in cities with the weakest social capital. Our IV results differ additionally in that, in the highest tercile of social capital, the coefficient on workplace diversity is both negative and not significantly related to wages. We interpret this cautiously, noting that the use of lags entail considerable loss of observations, as well as truncation of the duration of job spells.

\section{Conclusion}

This paper set out to answer the following question: do the effects of urban immigrant diversity on worker productivity depend on the inclusiveness of local institutions? The rationale for this question is rooted in a growing empirical literature seeking to understand the links between diversity and productivity. While studies in this area have become more sophisticated in their empirical approach, the extant work remains relatively distant from

Peri, 2006; Kemeny, 2012), as well as an annual measure capturing the presence of refugees in metropolitan areas, using information drawn from The Department of State's Refugee Processing Center. Neither of these instruments passed tests of instrument under- and overidentification. 
the underlying theory, which sites the mechanisms engendering positive or negative effects in interpersonal interactions. Since institutions are widely viewed to regulate the costs of such interactions, it makes sense to exploit variation in such institutions as a way to more carefully test the underlying theory. More practically, if institutions do indeed make a difference, findings could highlight the important function of local context. In addition to a more faithful test of theoretical ideas, this paper adds value to related work by building and triangulating across two measures of urban institutions, including one that is both novel and highly germane to this literature; by adopting an approach that accounts for non-random worker selectivity and a host of other potential threats to internal validity; and by exploring differential effects on the basis of nativity.

Results confirm our primary hypothesis. The wages of workers in cities that feature strongly inclusive institutions, whether measured by social capital or immigrant ordinances, respond much more sharply to changes in immigrant diversity in their urban context. The wages of the average worker inhabiting a city in the lowest tercile of social capital rise by 2.4 percent in response to a one standard deviation increase in metropolitan immigrant diversity. The average worker in a city in the highest tercile of social capital enjoys a 21 percent wage increase in response to a similar increase in diversity. As befits the sharper distinctions it draws, using our ordinance measure we detect no significant association between urban immigrant diversity and wages in cities featuring anti-immigrant ordinances, whereas the average worker in a metropolitan context featuring pro-immigrant laws receives a 36 percent wage increase. To put these numbers in context, the average change in diversity over the study period is approximately half a standard deviation, although immigrant diversity in a good number of metropolitan areas grows by a standard deviation, while in a handful of cities it expands by two standard deviations. Hence, although there is considerable variation across cities, the links between immigrant diversity and wages are not only statistically significant, but especially in cities endowed with inclusive institutions, diversity plays a substantively important role in influencing wages.

We also find evidence to suggest that natives and immigrants experience the moderating role of institutions differently. Broadly, foreign-born workers are more highly rewarded from rising diversity, offering support for the idea that they are more open to interacting with those from different backgrounds. Interestingly, and somewhat ironically, it appears 
that the workers who are most hurt from anti-immigrant ordinances belong to the very category of workers who are most likely to have supported them: natives. We find no evidence of an association between diversity and productivity for natives in cities with weakly inclusive institutions. Immigrants enjoy spillovers from immigrant diversity in cities of all kinds, but the rewards are considerably stronger in cities that have higher levels of social capital or pro-immigrant ordinances.

In seeking to better measure the relationship of interest, in this paper we adopted methods able to account for a wide range of threats to internal validity. Despite the careful empirical strategy, our ability to identify an independent causal relationship remains, as always, imperfect. One strength of our approach lies in its ability to absorb bias from relatively stationary factors at the individual, workplace and city scales. However unmeasured dynamic factors remain a concern. At the city level we account for shocks to the stock of college-educated workers and agglomeration, while at the workplace scale we capture changes in plant size. However, to the extent they are correlated with diversity, shocks to workplaces - such as increases in human capital or investment - could still inhibit accurate estimation of the relationship of interest. Our IV strategy helps address such concerns, but it cannot fully eliminate them. In part for this reason, our focus in this paper has been on the city scale, where we can be more confident of the results. Mismeasurement of inclusive institutions represents another potential concern. Indicators of latent variables will always contain measurement error, and this holds true for our social capital and ordinance indices. A related risk is that these indicators track unobserved factors unrelated to the underlying concept of interest. We responded to these challenges by triangulating across estimates produced with very different kinds of measures of the deeper latent concept. However, it remains possible that unobserved factors drive the differentiated results we observe. We hope that future studies will be able to more fully address these concerns, whether by exploiting exogenous shocks to institutions or through SEM-style models explicitly incorporating measurement error. Studies might also seek to measure institutions in individual workplaces, to observe how the ideas explored in this paper play out at that scale. We also reiterate limits on external validity that we imposed by focusing on firms with at least 10 employees, and by dropping the very lowest-income workers. There is consequently further work to be done to understand the impacts of 
immigrant diversity for these subpopulations.

Overall, our findings suggest that institutions - those "humanly devised constraints that structure political, economic and social interaction" (North, 1991) - play an important role in shaping the conditions in which diversity acts as a local productivity-enhancing public good. In a broader context in which American cities are becoming increasingly immigrant-diverse, the present paper suggests that policymakers have an incentive to find ways to lower the costs that workers born in different countries face in interacting with one another. Indeed, in cities that feature strongly inclusive institutions, growing immigrant diversity appears to offer concrete benefits to both natives and immigrants alike. 


\section{References}

Acemoglu, D. and Angrist, J. (2001). How large are human-capital externalities? evidence from compulsory-schooling laws. In NBER Macroeconomics Annual 2000, Volume 15, pages 9-74. MIT Press.

Acemoglu, D. and Robinson, J. (2012). Why Nations Fail: Origins of Power, Poverty and Prosperity. Crown Publishers (Random House).

Aiken, M. and Hage, J. (1971). The organic organization and innovation. Sociology, $5(1): 63-82$.

Alesina, A. and Drazen, A. (1991). Why are stabilizations delayed? The American Economic Review, 81(5):1170-1188.

Alesina, A., Harnoss, J., and Rapoport, H. (2013). Birthplace diversity and economic prosperity. Technical report, National Bureau of Economic Research.

Alesina, A. and La Ferrara, E. (2005). Ethnic diversity and economic performance. Journal of Economic Literature, 43(3):762-800.

Audretsch, D. B. and Feldman, M. P. (2004). Knowledge spillovers and the geography of innovation. In Henderson, J. and Thisse, J. F., editors, Handbook of Urban and Regional Economics, volume 4: Cities and Geography, pages 2713-2739. Elsevier.

Bairoch, P. (1991). Cities and economic development: From the dawn of history to the present. University of Chicago Press.

Bakens, J., Mulder, P., and Nijkamp, P. (2013). Economic impacts of cultural diversity in the Netherlands: Productivity, utility and sorting. Journal of Regional Science, $53(1): 8-36$.

Bellini, E., Ottaviano, G., Pinelli, D., and Prarolo, G. (2013). Cultural diversity and economic performance: Evidence from European regions. In Crescenzi, R. and Percoco, M., editors, Geography, institutions and regional economic performance, pages 121-142. Springer-Verlag.

Byrne, D. E. (1971). The attraction paradigm. Academic Press.

Card, D. (2001). Immigrant inflows, native outflows, and the local labor market impacts of higher immigration. Journal of Labor Economics, 19(1):22-64.

Chatman, J. A. and Flynn, F. J. (2001). The influence of demographic heterogeneity on the emergence and consequences of cooperative norms in work teams. Academy of Management Journal, pages 956-974.

Clearwater, S., Huberman, B., and Hogg, T. (1991). Cooperative solution of constraint satisfaction problems. Science, 254(5035):1181-1183.

Collier, P. (2000). Ethnicity, politics and economic performance. Economics 83 Politics, $12(3): 225-245$.

Combes, P., Duranton, G., and Gobillon, L. (2008). Spatial wage disparities: Sorting matters! Journal of Urban Economics, 63(2):723-742. 
Combes, P., Duranton, G., and Overman, H. (2005). Agglomeration and the adjustment of the spatial economy. Papers in Regional Science, 84(3):311-349.

Combes, P.-P., Duranton, G., and Gobillon, L. (2010). The identification of agglomeration economies. Journal of Economic Geography, page lbq038.

Easterly, W. and Levine, R. (1997). Africa's growth tragedy: Policies and ethnic divisions. Quarterly Journal of Economics, 112(4):1203-1250.

Easterly, W. and Levine, R. (2001). What have we learned from a decade of empirical research on growth? it's not factor accumulation: Stylized facts and growth models. The World Bank Economic Review, 15(2):177-219.

Elias, A. and Paradies, Y. (2016). The regional impact of cultural diversity on wages: evidence from australia. IZA Journal of Migration, 5(1):1-24.

Fujita, M. and Thisse, J.-F. (2013). Economics of agglomeration: cities, industrial location, and globalization. Cambridge university press.

Harrison, D. A. and Klein, K. J. (2007). What's the difference? diversity constructs as separation, variety, or disparity in organizations. Academy of Management Review, 32(4):1199-1228.

Hong, L. and Page, S. (2001). Problem solving by heterogeneous agents. Journal of Economic Theory, 97(1):123-163.

Hong, L. and Page, S. (2004). Groups of diverse problem solvers can outperform groups of high-ability problem solvers. Proceedings of the National Academy of Sciences of the United States of America, 101(46):16385-16389.

Huberman, B. (1990). The performance of cooperative processes. Physica D: Nonlinear Phenomena, 42(1):38-47.

Jacobs, J. (1969). The economy of cities. Random House.

Kemeny, T. (2012). Cultural diversity, institutions, and urban economic performance. Environment and Planning A, 44(9):2134-2152.

Kemeny, T. (2014). Immigrant diversity and economic performance in cities. International Regional Science Review, doi: 10.1177/0160017614541695.

Kemeny, T. and Cooke, A. (2015). Spillovers from immigrant diversity in cities. Technical report, LSE Spatial Economics Research Centre.

Kemeny, T. and Storper, M. (2012). The sources of urban development: Wages, housing and amenity gaps across american cities. Journal of Regional Science, 52(1):85-108.

Knack, S. and Keefer, P. (1997). Does Social Capital Have An Economic Payoff? A Cross-Country Investigation. Quarterly Journal of Economics, 112(4):1251-1288.

Lee, M. A. and Mather, M. (2008). U.S. labor force trends. Technical Report 63(2), Population Reference Bureau.

Lee, N. (2014). Migrant and ethnic diversity, cities and innovation: Firm effects or city effects? Journal of Economic Geography. 
Lewis, E. and Peri, G. (2014). Immigration and the economy of cities and regions. National Bureau of Economic Research Working Paper 20428.

Longhi, S. (2013). Impact of cultural diversity on wages, evidence from panel data. Regional Science and Urban Economics, 43(5):797-807.

Malecki, E. J. (2012). Regional social capital: why it matters. Regional Studies, 46(8):1023-1039.

McKinney, K. and Vilhuber, L. (2011). LEHD data documentation LEHD-OVERVIEWS2008-rev1. U.S. Census Bureau Center for Economic Studies Working Paper 11-43.

Montalvo, J. G. and Reynal-Querol, M. (2005). Ethnic diversity and economic development. Journal of Development Economics, 76(2):293 - 323.

Moretti, E. (2004a). Estimating the social return to higher education: evidence from longitudinal and repeated cross-sectional data. Journal of Econometrics, 121(1-2):175212.

Moretti, E. (2004b). Human capital externalities in cities. Handbook of regional and urban economics, 4:2243-2291.

Moretti, E. (2012). The New Geography of Jobs. Houghton Mifflin Harcourt.

Morgan, K. (2007). The learning region: institutions, innovation and regional renewal. Regional studies, 41(S1):S147-S159.

Nathan, M. (2011). The long term impacts of migration in British cities: Diversity, wages, employment and prices. LSE Spatial Economics Research Centre (SERC) Discussion Paper 67.

Nathan, M. (2014). The wider economic impacts of high-skilled migrants: a survey of the literature for receiving countries. IZA Journal of Migration, 3(1):4.

Nathan, M. (2015). Ethnic diversity and business performance and location: Which firms? which cities? Mimeo.

Nguyen, M. T. and Gill, H. (2015). Interior immigration enforcement: The impacts of expanding local law enforcement authority. Urban Studies, page 0042098014563029.

Nisbett, R., Ross, L., et al. (1980). Human inference: Strategies and shortcomings of social judgment. Prentice-Hall Englewood Cliffs, NJ.

North, D. C. (1991). Institutions. The Journal of Economic Perspectives, 5(1):97-112.

Oldenburg, R. (1989). The Great Good Place: Café, Coffee Shops, Community Centers, Beauty Parlors, General Stores, Bars, Hangouts, and How They Get You through the Day. Paragon House Publishers.

Ottaviano, G. and Peri, G. (2006). The economic value of cultural diversity: Evidence from US cities. Journal of Economic Geography, 6(1):9.

Özden, Ç., Parsons, C. R., Schiff, M., and Walmsley, T. L. (2011). Where on earth is everybody? the evolution of global bilateral migration 1960-2000. The World Bank Economic Review, 25(1):12-56. 
Page, S. (2008). The difference: How the power of diversity creates better groups, firms, schools, and societies. Princeton University Press.

Putnam, R. (2000). Bowling alone: The collapse and revival of American community. Simon and Schuster.

Rahn, W. and Transue, J. (1998). Social trust and value change: The decline of social capital in American youth, 1976-1995. Political Psychology, 19(3):545-565.

Roback, J. (1982). Wages, rents, and the quality of life. The Journal of Political Economy, 90(6).

Robinson, J. (2013). Why regions fail: The Mexican case. Mimeo.

Rodriguez, C. M. (2008). The significance of the local in immigration regulation. Michigan Law Review, pages 567-642.

Rodríguez-Pose, A. (1999). Innovation prone and innovation averse societies: Economic performance in europe. Growth and change, 30(1):75-105.

Ruggles, S., Alexander, J., Genadek, K., Goeken, R., Schroeder, M., and M., S. (2010). Integrated public use microdata series: Version 5.0. Technical report, Minneapolis, MN: Minnesota Population Center.

Rupasingha, A. and Goetz, S. (2008). US County-Level Social Capital Data, 1990-2005. The Northeast Regional Center for Rural Development.

Social Security Administration (2015). Measures of central tendency for wage data. https: //www.ssa.gov/oact/cola/central.html. Accessed: 07/21/2016.

Sparber, C. (2010). Racial diversity and aggregate productivity in US industries: 19802000. Southern Economic Journal, 75(3):829.

Stolle, D. and Hooghe, M. (2005). Inaccurate, exceptional, one-sided or irrelevant? The debate about the alleged decline of social capital and civic engagement in Western societies. British Journal of Political Science, 35(01):149-167.

Storper, M. (1995). The resurgence of regional economies, ten years later the region as a nexus of untraded interdependencies. European urban and regional studies, 2(3):191221.

Storper, M. (2013). Keys to the City: How Economics, Institutions, Social Interaction, and Politics Shape Development. Princeton University Press.

Storper, M., Kemeny, T., Makarem, N., and Osman, T. (2015). The Rise and Fall of Urban Economies: Lessons from San Francisco and Los Angeles. Stanford University Press.

Storper, M. and Scott, A. (2009). Rethinking human capital, creativity and urban growth. Journal of Economic Geography, 9(2):147.

Suedekum, J., Wolf, K., and Blien, U. (2014). Cultural diversity and local labour markets. Regional Studies, 48(1):173-191.

Tajfel, H. (1974). Social identity and intergroup behaviour. Social Science Information, 13(2):65-93. 
Taylor, C. and Hudson, M. (1972). World Handbook of Political and Social Indicators. Yale University Press.

Thomas, D. and Ely, R. (1996). Making differences matter. Harvard Business Review, 74(5):79-90.

Trax, M., Brunow, S., and Suedekum, J. (2015). Cultural diversity and plant-level productivity. Regional Science and Urban Economics, 53:85-96.

Turner, J. C., Hogg, M. A., Oakes, P. J., Reicher, S. D., and Wetherell, M. S. (1987). Rediscovering the social group: A self-categorization theory. Basil Blackwell.

Valentine, G. and Sadgrove, J. (2014). Biographical narratives of encounter: The significance of mobility and emplacement in shaping attitudes towards difference. Urban Studies, 51(9):1979-1994.

Van Knippenberg, D. and Schippers, M. C. (2007). Work group diversity. Annual Review of Psychology, 58:515-541.

Varsanyi, M. W. (2008). Immigration policing through the backdoor: City ordinances, the "right to the city," and the exclusion of undocumented day laborers. Urban Geography, 29(1):29-52.

Walker, K. E. and Leitner, H. (2011). The variegated landscape of local immigration policies in the united states. Urban geography, 32(2):156-178.

Wilson, J. H. and Svajlenka, N. P. (2014). Immigrants continue to disperse, with fastest growth in the suburbs. Brookings Immigration Facts Series, No. 18.

Woolcock, M. and Narayan, D. (2000). Social capital: Implications for development theory, research, and policy. The world bank research observer, 15(2):225-249. 
Table 1: Factor Loadings: Social Capital Indicator, 2007

\begin{tabular}{lcc}
\hline Variable & Loading & Uniqueness \\
\hline Associations & 0.73 & 0.42 \\
Third Places & 0.76 & 0.46 \\
Census Response Rates & 0.73 & 0.46 \\
Voter Turnout & 0.84 & 0.29 \\
\hline
\end{tabular}


Table 2: Strongest and Weakest CBSAs According to their Levels of Social Capital

\begin{tabular}{ll}
\hline Highest Social Capital & Lowest Social Capital \\
\hline Appleton, WI & McAllen-Edinburg-Mission, TX \\
Des Moines-West Des Moines, IA & Fayetteville, NC \\
Green Bay, WI & Lakeland-Winter Haven, FL \\
Billings, MT & Riverside-San Bernardino-Ontario, CA \\
Portland-South Portland-Biddeford, ME & Bakersfield-Delano, CA \\
Cedar Rapids, IA & Killeen-Temple-Fort Hood, TX \\
Milwaukee-Waukesha-West Allis, WI & El Paso, TX \\
Eugene-Springfield, OR & Houston-Sugar Land-Baytown, TX \\
Davenport-Moline-Rock Island, IA-IL & Fresno, CA \\
Trenton-Ewing, NJ & Beaumont-Port Arthur, TX
\end{tabular}

Note: Authors' calculations as described in Section 4.3.1, based on underlying data drawn from County Business Patterns and other sources. 
Table 3: Pro- and Anti-Immigrant Ordinances: Top Ten CBSA ranked according to the proportion of the population covered by ordinances

\begin{tabular}{ll}
\hline Widest Pro-Immigrant Coverage & Widest Anti-Immigrant Coverage \\
\hline Madison, WI & Charlotte-Concord-Gastonia, NC-SC \\
Salem, OR & Palm Bay-Melbourne-Titusville, FL \\
Santa Rosa, CA & Green Bay, WI \\
Chicago-Naperville-Elgin, IL-IN-WI & Appleton, WI \\
El Paso, TX & Houston-The Woodlands-Sugar Land, TX \\
Albuquerque, NM & Fayetteville-Springdale-Rogers, AR-MO \\
San Jose-Sunnyvale-Santa Clara, CA & Tulsa, OK \\
Fresno, CA & Riverside-San Bernardino-Ontario, CA \\
Austin-Round Rock, TX & Burlington, NC \\
Santa Fe, NM & Harrisonburg, VA \\
\hline
\end{tabular}

Note: Authors' calculations as described in Section 4.3.2, based on data from Walker and Leitner (2011). 
Table 4: Summary Statistics on Full Analytical Sample

\begin{tabular}{llc}
\hline Variable & Mean & Standard Deviation \\
\hline Individual Characteristics & & \\
$\quad$ Log Annual Earnings & 10.48 & 0.637 \\
Age & 40.32 & 11.67 \\
White & 0.667 & 0.471 \\
U.S. Born & 0.840 & 0.366 \\
Female & 0.467 & 0.499 \\
$\quad$ Spell Duration & 4.970 & 3.304 \\
Establishment Characteristics & & \\
$\quad$ Birthplace Fractionalization & 0.220 & 0.207 \\
Employment & 63.01 & 278.39 \\
Multi-Unit & 0.349 & 0.477 \\
City Characteristics & & \\
$\quad$ Birthplace Fractionalization & 0.180 & 0.129 \\
College Share, All Workers & 0.256 & 0.074 \\
$\quad$ Employment (10,000s) & 47.20 & 88.29 \\
\hline Individuals & $33,550,000$ & \\
Establishments & $1,193,000$ & \\
CBSAs & 163 & \\
\hline
\end{tabular}

All data displayed in this table are drawn from LEHD, except for city college share, which is built from public-use IPUMS data. 
Table 5: Fixed Effects Estimates of Relationship between Immigrant Diversity and Log Annual Wages by Two Measures of Inclusive Institutions

\begin{tabular}{|c|c|c|c|c|c|}
\hline & \multirow{2}{*}{$\begin{array}{c}\text { Full } \\
\text { Sample } \\
(1)\end{array}$} & \multicolumn{2}{|c|}{ Social Capital } & \multicolumn{2}{|c|}{ Immigrant Ordinances } \\
\hline & & $\begin{array}{l}\text { Low } \\
(2)\end{array}$ & $\begin{array}{c}\text { High } \\
(3)\end{array}$ & $\begin{array}{l}\text { Anti } \\
(4)\end{array}$ & $\begin{array}{c}\text { Pro } \\
(5)\end{array}$ \\
\hline \multicolumn{6}{|l|}{ City-Level Measures } \\
\hline Birthplace Fractionalization & $\begin{array}{c}0.375^{* * *} \\
(0.065)\end{array}$ & $\begin{array}{c}0.168^{* *} \\
(0.066)\end{array}$ & $\begin{array}{c}0.969^{* * *} \\
(0.298)\end{array}$ & $\begin{array}{c}0.099 \\
(0.098)\end{array}$ & $\begin{array}{c}1.314^{* * *} \\
(0.129)\end{array}$ \\
\hline College Share & $\begin{array}{c}0.162^{* * *} \\
(0.040)\end{array}$ & $\begin{array}{c}-0.522^{* * *} \\
(0.062)\end{array}$ & $\begin{array}{c}0.093 \\
(0.103)\end{array}$ & $\begin{array}{c}-0.260^{* * *} \\
(0.062)\end{array}$ & $\begin{array}{c}0.065 \\
(0.099)\end{array}$ \\
\hline Employment (milions) & $\begin{array}{c}0.031^{* * *} \\
(0.005)\end{array}$ & $\begin{array}{c}0.027^{* * *} \\
(0.006)\end{array}$ & $\begin{array}{c}0.096^{* * *} \\
(0.022)\end{array}$ & $\begin{array}{c}0.037^{* * *} \\
(0.007)\end{array}$ & $\begin{array}{c}-0.058^{* * *} \\
(0.018)\end{array}$ \\
\hline \multicolumn{6}{|c|}{ Establishment-Level Measures } \\
\hline Birthplace Fractionalization & $\begin{array}{c}0.073^{* * *} \\
(0.007)\end{array}$ & $\begin{array}{c}0.051^{* * *} \\
(0.006)\end{array}$ & $\begin{array}{c}0.086^{* * *} \\
(0.024)\end{array}$ & $\begin{array}{c}0.069^{* * *} \\
(0.007)\end{array}$ & $\begin{array}{c}0.087^{* * *} \\
(0.014)\end{array}$ \\
\hline Employment (thousands) & $\begin{array}{c}0.006^{*} \\
(0.003)\end{array}$ & $\begin{array}{c}0.003 \\
(0.003)\end{array}$ & $\begin{array}{c}0.009^{*} \\
(0.005)\end{array}$ & $\begin{array}{c}0.001 \\
(0.002)\end{array}$ & $\begin{array}{c}0.020^{* * *} \\
(0.006)\end{array}$ \\
\hline Observations (millions) & 166.5 & 73.67 & 29.70 & 41.05 & 22.67 \\
\hline Individuals (millions) & 33.5 & 15.28 & 5.48 & 8.19 & 4.44 \\
\hline$R^{2}$ & 0.95 & 0.95 & 0.94 & 0.95 & 0.95 \\
\hline
\end{tabular}




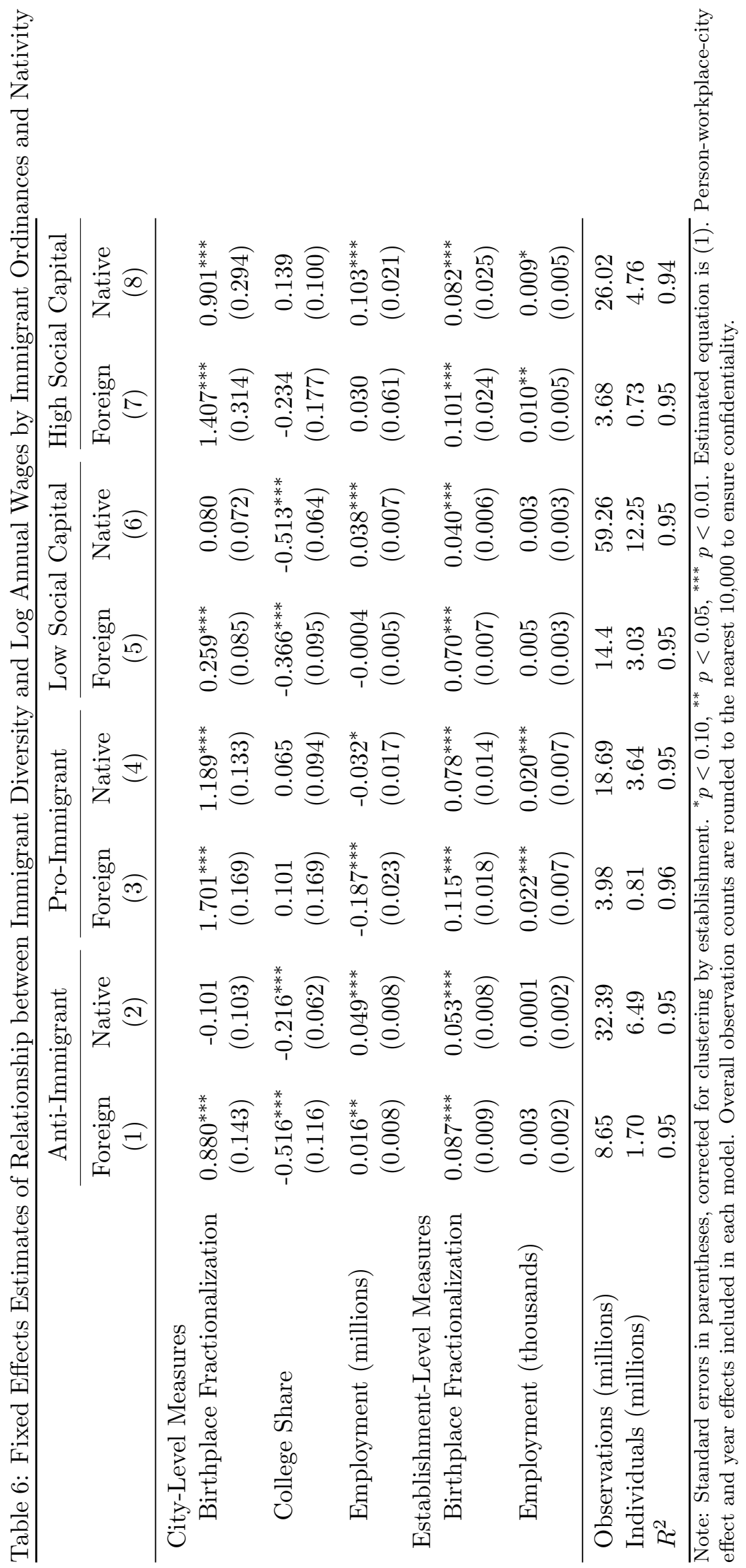


Table 7: GMM FE Instrumental Variables Estimates

\begin{tabular}{lcc}
\hline & $\begin{array}{c}\text { Low Social } \\
\text { Capital } \\
(1)\end{array}$ & $\begin{array}{c}\text { High Social } \\
\text { Capital } \\
(2)\end{array}$ \\
\hline City-Level Measures & & \\
Birthplace Fractionalization & 0.001 & $1.979^{* *}$ \\
& $(0.122)$ & $(0.896)$ \\
College Share & $-0.165^{* *}$ & 0.258 \\
& $(0.067)$ & $(0.190)$ \\
Employment (millions) & $0.012^{*}$ & 0.078 \\
& $(0.007)$ & $(0.055)$ \\
Establishment-Level Measures & & \\
Birthplace Fractionalization & $0.092^{* * *}$ & -0.634 \\
& $(0.031)$ & $(0.396)$ \\
Employment (thousands) & $0.006^{*}$ & -0.0004 \\
& $(0.003)$ & $(0.002)$ \\
\hline Observations (millions) & 22.27 & 8.42 \\
Individuals (millions) & 4.66 & 1.56 \\
Kleibergen-Paap first-stage $F$ & 1732 & 76 \\
Hansen $J$ & 2.18 & 0.001 \\
Hansen $J p$-value & 0.14 & 0.98
\end{tabular}

Note: Standard errors in parentheses, corrected for clustering by establishment. ${ }^{*} p<0.10,{ }^{* *} p<0.05$, ${ }^{* * *} p<0.01$. Estimated equation is (1). Person-workplace-city effect and year effects included in each model. Overall observation counts are rounded to the nearest 10,000 to ensure confidentiality. 